\title{
Study of the forecasting problem of energy consumption of water pumping station*
}

\author{
Aleksandr V. Alekseev ${ }^{1}$ \\ ${ }^{1}$ Melentiev Energy Systems Institute of Siberian Branch of the Russian Academy of Sciences (ESI \\ SB RAS), Pipeline Systems Department, 130, Lermontov str., Irkutsk, Russia, 664033
}

\begin{abstract}
The article describes the study of the energy consumption forecasting of city water pumping station. The review of the existing approaches for technical systems energy consumption forecasting is made. The shot description of the studied object properties including hourly energy consumption is presented. Two often used forecasting methods exponential smoothing and the autoregression of the integrated moving average methods was tested on real data. The results of predict calculations shows that the autoregression of the integrated moving average methods is suitable for energy consumption planning and can be used to submit an hourly bid for the required amount of the electricity in the wholesale market. Directions for future research is also presented.
\end{abstract}

\section{Introduction}

The transition to market relations between large consumers and electricity producers was stimulated by presidential decree of June 4, 2008 No. 889 "On some measures to improve the environmental and energy efficiency of Russia". In this regard, all major consumers of electricity (including urban pipeline systems) began to develop measures to improve energy efficiency, and as a result increase competitiveness and profits. Two-tier market structure (wholesale and retail markets) and separate circulation of electricity and power (market of two goods) were taken as the basis for electricity in Russia. The price of electricity on the wholesale market is determined by the balance of supply and demand. This price, as a rule, is lower than the price in the retail market at least due to the absence of a premium of the guaranteeing supplier. One of the key requirements for participation in the wholesale market for electricity and power (WMEP) is the need to submit an hourly bid for the required amount of the electricity one day in advance. Thus, all large electricity buyers are faced with the problem of forecasting of consumed electrical energy volume. Deviations of actual consumption from the previously required leads to the appearance of penalties from the wholesale market.

In this paper, the problem of the energy consumption forecasting of water supply enterprises in Russian cities with the aim of purchasing electricity on the WMEP is devoted.

\footnotetext{
*Corresponding author: asanya@mail.ru
} 


\section{Existing approaches to forecasting technical processes and analyzing their applicability}

The forecasting methods can be divided into three groups [1]: heuristic, analytical, and factographic. The first group includes expert assessments, methods of analogies, scenarios, a goal tree method, etc. They are characterized by the active involvement of a person, his knowledge and experience in the process of making a forecast. Analytical methods are based on well-defined algorithms and formulas. Analytical methods include interpolation and extrapolation methods. Factographic methods are based on available observational data (retrospective assessment). These include correlation and regression analysis, the exponential smoothing method, the autoregression of the integrated moving average (ARIMA models), the theory of random processes and time series theory. Regression models have found the widest application, because of their simplicity and sufficient accuracy in analyzing seasonal and daily fluctuations. At the same time, regression models do not accurately predict nonstandard events, such as holidays. In practice, a combination of these methods is often used. Recently, thanks to the development of modern information technologies, forecasting models based on genetic algorithms and artificial neural networks (ANN) have become widespread in practice [2, 3, and others]. The main advantages of the ANN are the absence of the need to construct a model of the object and the stability of the model with incomplete or unreliable input information.

The literature we can find a large number of different forecasting methods used in the power industry, which is a combination of various statistical approaches. These are classical (deterministic, stochastic) [4-7] and intellectual (machine learning algorithms, expert systems, fuzzy logic) methods [8-12].

In papers [4-12], the main emphasis is placed on the selection of seasonal, daily fluctuations of energy consumption. To clarify the accuracy of forecast in the model the outdoor temperature, wind speed, light, social, market and other "meta-factors" are taking into account. Accounting for these additional factors allows to reduce the forecast error. All the works described above cannot be directly used in solving the problem posed in the article, because they initially focused on the demand forecasting of a large number of small consumers (population, social and cultural enterprises and small enterprises), the total probability of which electricity consumption is distributed according to normal law. Water supply enterprises operate according to the regulations, so the hypothesis about the normal distribution of the probability of energy consumption is not confirmed.

Considerable experience in solving forecasting problems is also in the field of pipeline systems modeling [13-24]. The problem of gas consumption forecasting in the process of gas main-pipelines modeling were considered in [13], forecasting the load of the heating network [14], water consumption in urban engineering networks [15]. In the works [16-22], water consumption predictions are built with help of various methods, based on which the tasks of equipment optimization and network development are subsequently solved. In the works $[23,24]$ it is told about successful solution of the problem of energy and water consumption forecasting in "Mosvodokanal"(Moscow Water Supply Company). According to the authors, they managed to achieve high prediction accuracy (forecast error about 1-2\%). However, in their publications, the authors report only about the statement of the successful solution of the problem posed and the implementation of the software complex, without description of the mathematical apparatus, which allowed the authors to solve the posed problem successfully. 


\section{The substantive statement of the problem}

As already mentioned, the goal of this work is to predict the energy consumption of water supply companies. At these companies, energy consumption is associated with the operation of pumping equipment at water intake facilities, pumping stations, sewage pumping stations and sewage treatment plants. Since all the listed facilities have independent connection to the power grids and have their own meters, the process of energy consumption of these facilities can be considered independently of each other. Although in the general case the task should be considered systemically.

Energy consumption of water supply and water utilities enterprises is determined by the operating modes of pumping stations, which depend on the water consumption of the city, the rules for filling tanks and the amount of leakages in the network. External factors also have their influence: economic, natural, climatic. Separately, it is worth noting the influence of energy supplying organizations that prescribe the reduction of energy consumption at certain (most often peak) hours.

Generally speaking, the task of energy consumption forecasting should be solved as optimization problem, based on the forecasting of water consumption processes, optimal loading of pumping equipment, optimization of hydraulic modes of the network, tank filling schedule, taking into account natural and other external factors. Joint consideration of all these tasks is a complex problem requiring special consideration. This paper presents the results of the first stage of the study, in which the random process of energy consumption is considered as a time series. The Black box, the power consumption of which depends only on the time factor. The real data of the hourly energy consumption of the water supply pumping station for a period of 10 months was used as the initial data.

\section{Analysis of the properties of energy consumption processes}

The goal of the analysis is to identify trends, systematic and periodic components, as well as the selection of models to describe these components in the background noises. In analyzing the data, formal methods were used - the method of sequential elimination of components, and heuristic, involving the explanation of certain trends and regularities.

Energy consumption of a single pumping station (PS) was considered. The PS has 7 parallel-connected pumping units of two types with a capacity of $630 \mathrm{~kW}$ and $320 \mathrm{~kW}$, respectively. Depending on the time of day and the pressure in the network, one, two or three pumps work at the pumping station.

In Fig.1. Graph of hourly electricity consumption in the PS in July 2017 is presented.

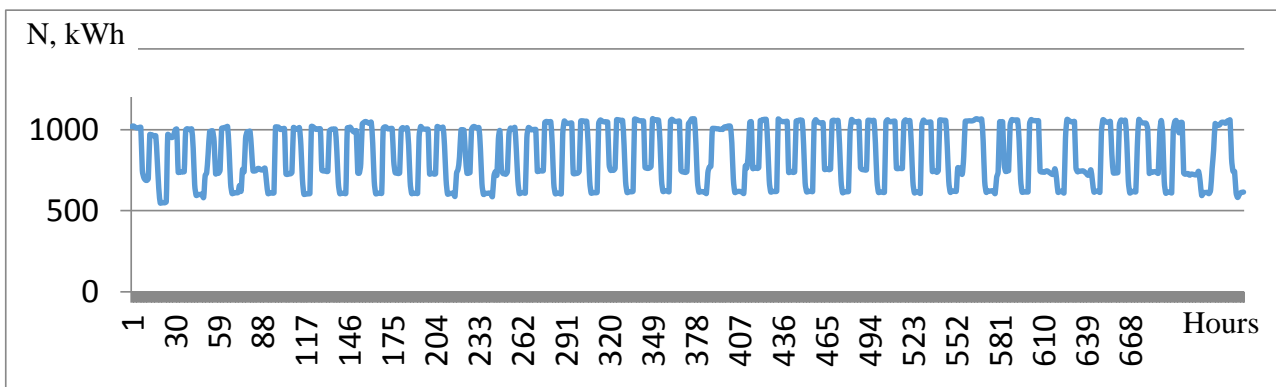

Fig.1. Hourly power consumption at the pumping station in July 2017.

The study of the autocorrelation function of energy consumption (Fig. 2) showed that events that occurred no more than a month ago had a significant influence on the process, 
and consumption at the same hour a day and a week ago had the greatest effect. Thus, when forecasting energy consumption, the main guideline should be the data on energy consumption on the corresponding day of the week and hour in the last month.

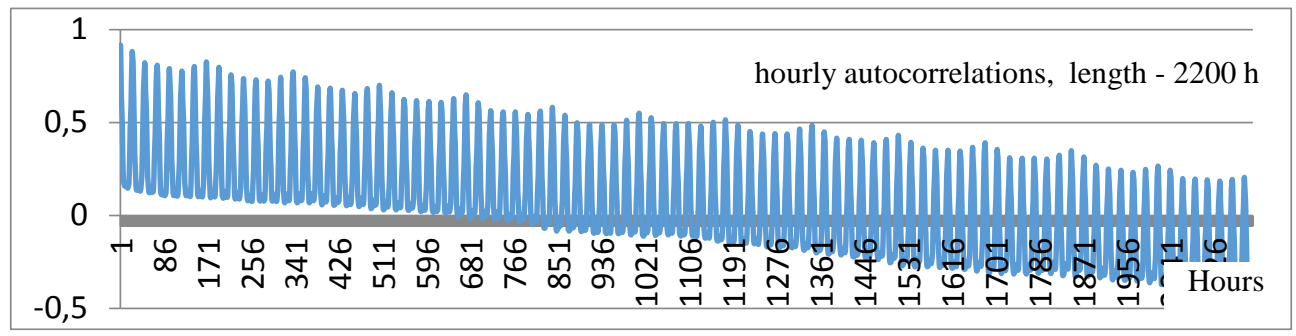

Fig.2. Autocorrelation function of daily energy consumption.

Studies of weekly uneven energy consumption showed a slight variation in days of the week. The difference is not more than $3 \%$. The scatter of the values of the mean root square deviation is also minimal and does not exceed $6 \%$.

\section{Prediction of energy consumption of the pumping station}

To predict the power consumption of the pumping station, the Exponential Smoothing Method (ESM) was used. The ESM is a generalization of the moving average method and allows us to construct a description of the predicted process in which more weight is given to later observations, compared to earlier observations, and the "weights" of observations decrease exponentially.

Despite the fact that the ESM gives more weight to the latter values, reducing the weight of more distant events, an increase in the length of the prehistory in question affects the forecast negatively. With an increase in the length of the considered history to 120 days and the prediction of the same dates, there is a noticeable deterioration in the accuracy of the forecast. The average error is $9 \%$, in some hours reaching $21 \%$.

As can be seen from fig. 3 , in certain periods of time, the PS energy consumption graph (blue line) is rather stable. When predicting such fragments, a satisfactory result was obtained. So, with the forecast of energy consumption (bold orange line), the average error was about $3.5 \%$, maximum error was $15 \%$, the length of the retrospective data under review was 20 days (Fig. 3a). At the same time, in certain periods of the year (Fig. 3b), the energy consumption graph has a more complex form (consumption is characterized by significant stochastics), in this case, the forecast error increases to $10-12 \%$, with maximum $26 \%$ in a specific hours.

a)

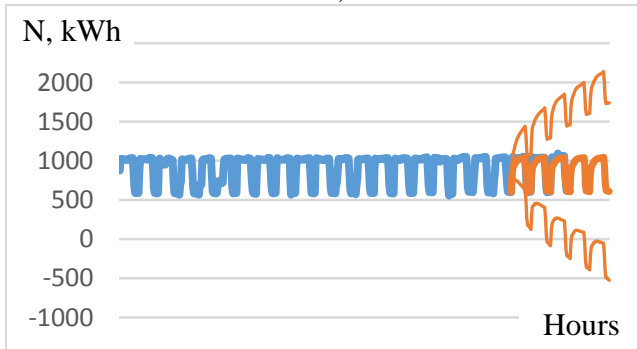

b)

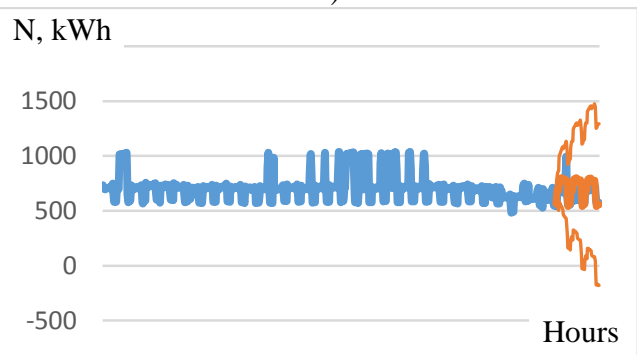

Fig. 3. The forecast of PS energy consumption. a) in "good" period; b) in "bad" period. 
Thus, the accuracy that the ESM provides for most of the data is not sufficient to make reliable predictions of the PS energy consumption.

The most commonly used in energy forecasting is the ARIMA model. This is a general model proposed by Box and Jenkins [25] in 1974, which includes both autoregressive parameters and moving average parameters. There are three types of model parameters: autoregression parameters (p), difference order (d), moving average parameters (q). The selection of these parameters is a separate, well-described task and is not considered in this paper.

Forecasting using the ARIMA model was carried out in the Statistica package. The choice of model parameters was carried out on the basis of the analysis of the autocorrelation function and the use of the operator of taking consecutive differences. For correctness of the comparison, the forecast was built at the same points in time as it was used in ESM . The forecast results are shown in Fig.4. The forecast error in the first case was $2.4 \%$ on the first day and $2.7 \%$ on the second, reaching $15 \%$ in the specific hour of the day.

a)

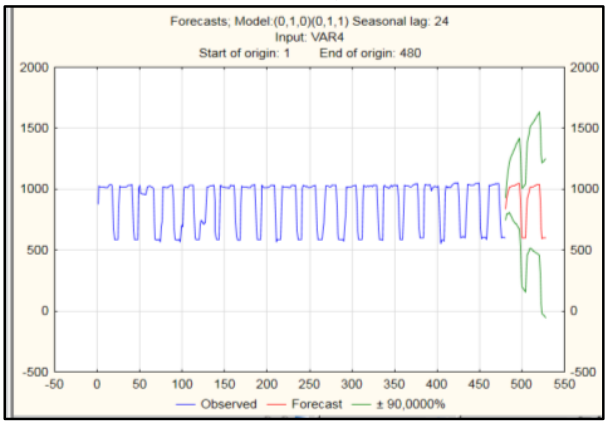

b)

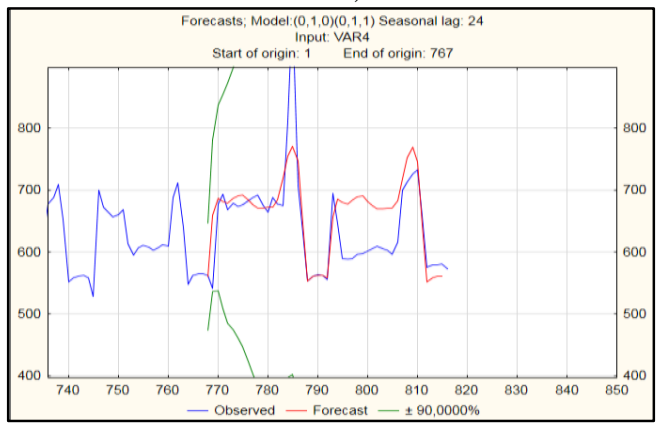

Fig.4. a) forecast in "good" period; b) forecast in "bad" period.

When building a forecast in "bad" period (Fig. 4b), the error was about $4.4 \%$ on the first day and $9.6 \%$ on the second, which is significantly better than the result shown by the ESM.

\section{Conclusion}

As opposed to the generally accepted approach to the energy consumption forecast of an enterprise as a whole, an attempt to predict an energy consumption of the single water pumping station was made. It is shown that the process of energy consumption of a single object is largely determined by the regulations. The two most popular forecasting models with the only time factor were considered. The ARIMA model showed acceptable accuracy in the range of $2-5 \%$, which is enough for making bids in the wholesale electricity market.

In the future works, to reduce the forecasting error, it is necessary to proceed to the consideration of several factors (weather, holidays, regulations), as well as water supply forecasting to clarify the energy consumption forecast. The author considers it is necessary to study the applicability of other models, first of all - neural networks. At the same time, in order to achieve a higher quality forecast, it is necessary to make changes to the regulations of PS, filling-emptying tanks schedules and to organize their coordinated work.

The research was carried out within the project III.17.4.3 of the Fundamental research program of $S B$ RAS (AAAA-A17-117030310437-4) 


\section{References}

1. M.G. Sukharev, Forecasting methods. Study Guide (2009) [in Russian]

2. S.T. Chen, C.Y. David, A.R. Moghaddamjo, IEEE Trans. on Power Systems, 7 (3), 1098 (1992)

3. P.K. Dash, G. Ramakrishna, A.C. Liew, S. Rahman, IEE Proc. Gener. Transm. Distrib, 142 (5), 535 (1995) (1990)

4. W. R. Christiaanse, IEEE Trans. On Power Appar. Syst, 3, 900 (1998)

5. A. D. Papalexopoulos, T. Hasterberg, IEEE Trans. On Power Systems, 5 (4), 1535

6. S. R. Haung, IEE Proc. Gener. Trans. Distrib., 144 (5), 477 (1997)

7. H.S. Hippert, IEEE Trans. On Power Systems, 16 (1) (2001)

8. G. P. Shumilova, N. E. Gotman, T. B. Startseva, Prediction of electrical loads in the operational management of electric power systems based on neural network structures (UB RAS, Ekaterinburg, 2008) [in Russian]

9. V.G. Kurbatsky, Elektrika, 7, 26 (2006) [in Russian]

10. N. Tomin, A. Zhukov, D. Sidorov, V. Kurbatsky, D. Panasetsky, V. Spiryaev, International Journal of Artificial Intelligence, 13 (1), 211 (2015)

11. M. Adya , F. Collopy, J. Forecast, 17, 481 (1998)

12. V.N. Kornilov, V.G. Kurbatsky, N.V. Tomin, Proc. Research and Ensuring the Reliability of Energy Systems, 68, 682 (2017) [in Russian]

13. M. G. Sukharev, E. R. Stavrovsky, Optimization of Gas Transportation Systems (Nedra, Moscow, 1975) [in Russian]

14. G. Suryanarayana, J. Lago, D. Geysen, and others, Energy, 157, 141 (2018)

15. A.G. Evdokimov, A.D. Tevyashev, V.V. Dubrovsky Modeling and optimization of flow distribution in engineering networks (Stroyizdat, Moscow, 1990) [in Russian]

16. P. Cutore, A. Campisano, Z. Kapelan, C. Modica \& D. Savic, Urban Water Journal, 5:2, 125 (2008)

17. Water Efficiency of Pumping Operations. AwwaRF, 2007 http://www.waterrf.org/PublicReportLibrary/91189.pdf

18. M. Fullerton Jr., Angel L. Molina Jr., Water resources research, 46, W06515 (2010)

19. J.-D. Rinaudo, Understanding and Managing Urban Water in Transition, 239 (2015)

20. J. Wackerbauer, Open Access Library Journal, 4, e3425 (2017)

21. P. Chronis, G. Giannopoulos, S. Athanasiou, Workshop Proceedings of the EDBT/ICDT, 1558 (2016)

22. H. Assem, S. Ghariba, G. Makrai, P. Johnston, L. Gill, and F. Pilla, Proc. Machine Learning and Knowledge Discovery in Databases, 317 (2017)

23. Ye. V. Shushkevich, Water supply and sanitary equipment, 1, 24 (2011) [in Russian]

24. K.E. Khrenov, A. A. Potyomin, S. I. Sapozhnikov, Water supply and sanitary equipment, 10, 65 (2010) [in Russian]

25. G. Box, G. Jenkins, Time Series Analysis: Forecasting and Control (Holden-Day, San Francisco, 1970) 